\title{
Potenciais alternativas com extratos vegetais no controle da pinta preta do tomateiro
}

\section{Potential alternatives with vegetable extracts in control of tomato early blight}

\author{
Edvan Nilson de Almeida ${ }^{1}$; Gabriela Silva Moura ${ }^{2}$; Gilmar Franzener ${ }^{3}$
}

Resumo: Objetivou-se com o presente estudo avaliar o potencial antifúngico de três espécies de plantas medicinais: Zingiber officinale (gengibre), Allium sativum L. (alho) e Caryophyllus aromaticus L. (cravo-da-índia) in vitro e in vivo, para o controle do patógeno Alternaria solani, agente causal da pinta preta. Avaliou-se in vitro o crescimento micelial, germinação de esporos e o tamanho de tubos germinativos de A. solani nas concentrações de 1,0, 5,0,10, 15 e 20\%. Para a avaliação in vivo sementes de tomateiro cv. Santa Cruz Kada foram semeadas em bandejas de isopor de 200 células contendo substrato comercial. Após 30 dias as mudas foram transplantadas para vasos de $5 \mathrm{~L}$ contendo solo e mantidas em casa de vegetação. Os tratamentos para o ensaio em in vivo foram extrato aquoso de gengibre, alho e cravo-da-índia na concentração de $20 \%$. As aplicações foram iniciadas após 47 dias do transplante das mudas para casa de vegetação, sendo realizada uma vez por semana até o momento da colheita. Foram realizadas avaliações da área abaixo da curva de progresso da doença (AACPD), número médio e peso de frutos. Os experimentos foram conduzidos em delineamento inteiramente casualizado, com cinco repetições. Os extratos de cravo-da-índia, alho e gengibre apresentaram efeito inibidor direto sobre o fungo e reduziram a AACPD em 55,8, 29,5 e 22,5\% em relação à testemunha água, respectivamente. Esses resultados indicam potencial dos extratos vegetais avaliados no controle da pinta preta do tomateiro, com destaque para o extrato de cravo-da-índia.

Palavras-chave: Solanun lycopersicon; Gengibre; Alho; Cravo-da-índia.

\begin{abstract}
The objective of this study was to evaluate the antifungal potential of three species of medicinal plants: Zingiber officinale (ginger), Allium sativum L. (garlic) and Caryophyllus aromaticus L. (clove) in vitro and in vivo, for the control of the pathogen Alternaria solani, causal agent of the black pint. Mycelial growth, spore germination and germination size of $A$. solani were evaluated in vitro at concentrations of 1.0, 5.0, 10, 15 and 20\%. For the in vivo evaluation of tomato seeds cv. Santa Cruz Kada were seeded in styrofoam trays of 200 cells containing commercial substrate. After 30 days the seedlings were transplanted to $5 \mathrm{~L}$ pots containing soil and kept in a greenhouse. The treatments for the in vivo assay were aqueous extract of ginger, garlic and clove at $20 \%$ concentration. The applications were started after 47 days of transplanting the greenhouse, being carried out once a week until the time of harvest. Evaluations of the area under the disease progress curve (AACPD), mean number and fruit weight were performed. The experiments were conducted in a completely randomized design with five replicates. Clove, garlic and ginger extracts showed a direct inhibitory effect on the fungus and reduced the AACPD in 55.8, 29.5 and $22.5 \%$ in relation to the control water, respectively. These results indicate the potential of the extracts evaluated in the control of the black peat of tomato, with emphasis on clove extrac.
\end{abstract}

Keywords: Solanun lycopersicon; Ginger; Garlic; Clove.

\footnotetext{
*Autor para correspondência

Recebido para publicação em 06/04/2016; aprovado em 04/09/2017

${ }^{1}$ Engenheiro Agrônomo, Universidade Federal da Fronteira Sul (UFFS), E-mail: edvanalmeida14@hotmail.com

${ }^{2}$ Pós-doutoranda em Agroecologia e Desenvolvimento Rural Sustentável (PNPD-CAPES), Universidade Federal da Fronteira Sul (UFFS), E-mail: bismoura@hotmail.com

${ }^{3}$ Professor da Universidade Federal da Fronteira Sul (UFFS), Campus Laranjeiras do Sul - PR. E-mail: gilmar.franzener@uffs.edu.br
} 


\section{INTRODUÇÃO}

O tomateiro (Solanun lycopersicon Mill.) é uma das culturas mais importantes no mundo do ponto de vista econômico (KUROZAWA; PAVAN 2005, FIGUEIRA, 2007). A produção nacional do tomate vem progredindo nitidamente durante décadas, como pode ser verificado quando comparado à produção no ano de 1990 a qual foi de 2.260.871 toneladas, já no ano de 2012 a produção nacional teve um expressivo aumento alcançando 3.873.985 toneladas (FAO-FAOSTAT, 2015).

O Brasil ocupa a oitava posição na classificação mundial de produção de tomate, com um volume de aproximadamente de 3,7 milhões de toneladas, com produtividade de $63,7 \mathrm{t} / \mathrm{ha}^{-1}$, em 2015 (IBGE, 2015).

A planta de tomate origina um fruto muito apreciado mundialmente, caracterizado por ser carnoso e suculento. Além disso, a cultura do tomateiro também possui grande importância nutricional em virtude dos nutrientes de sua composição, sendo que entre os principais está o carotenoide licopeno responsável pela sua coloração (FILGUEIRA, 2007).

A cultura do tomateiro é muito exigente em mão de obra propiciando a geração direta e indireta de emprego. No entanto, a produção de tomate é considerada uma atividade de risco pelo fato, da cultura ser acometida por várias doenças que podem comprometer seu desenvolvimento e sua produção (JANTASORN et al., 2016). Entre os agentes causais estão às bactérias, fungos, vírus e nematoides que dificultam o cultivo e causam grandes perdas de rendimento em numerosas culturas importantes (HUANG et al., 2010).

O patógeno Alternaria solani (Ell. \& Martin) Jones \& Grout, agente causal da pinta preta, vem causando perdas significativas na produção do tomateiro podendo chegar até $75 \%$. O uso indiscriminado de agroquímicos na cultura do tomate resulta na intensificação das doenças e da contaminação ambiental, além da exposição dos consumidores a alimentos contaminados com agrotóxicos (ARAÚJO et al., 2000, KISHORE; PANDE, 2007, FAWZI et al., 2009).

Segundo o relatório do Programa de Análise de Resíduos de Agrotóxicos em Alimentos, no período 2013 a 2015, de 730 amostras de tomate de mesa analisadas, em 62 foi identificado a presença de resíduos acima do LMR (Limite Máximo de Resíduos), e 200 apresentaram agrotóxicos não autorizados para cultura (ANVISA, 2016). Uma das limitações para manejo da doença é a escassez de cultivares comerciais de tomates resistentes à pinta preta (ARAUJO; MATSUOKA, 2004), e as medidas de controle têm sido basicamente a utilização de produtos químicos que em algumas situações pode elevar o custo de produção, além de ser prejudicial ao meio ambiente devido aos fungicidas altamente persistentes e pouco seletivos, ocasionando alterações na biodiversidade do local (MIRANDA; RELS, 2006).

Neste sentido, a agricultura moderna tem buscado alternativas agroecológicas, como a utilização de derivados vegetais (extratos, óleos essenciais, hidrolatos dentre outros) que podem levar a descoberta de agentes antimicrobianos com possíveis novos mecanismos de ação contra fitopátogenos.

Segundo Tapwal et al. (2011), a presença de composto antifúngicos em plantas superiores já é reconhecida como fonte de bio-pesticida vegetal para o controle de doenças em plantas. Existe grande interesse pelos pesquisadores na aplicação de produtos vegetais como bio-pesticida (SINGH; SRIVASTAVA, 2013), pois através do uso desses produtos vegetais, pode haver uma diminuição no uso de pesticidas químicos que têm um efeito indesejável na cadeia alimentar dos organismos presentes no ambiente e nos seres humanos. Além disso, os bio-pesticidas de planta são baratos, disponíveis localmente, não tóxicos, e são facilmente degradáveis (JANTASORN et al., 2016). Diante deste contexto, estudos relacionados a produção agroecológica dispõem de métodos alternativos, como a utilização de derivados vegetais com ação bio-pesticida para o controle do patógeno A. solani, conforme evidencias em plantas de solanáceas (DILL, 2009; FRANZENER et al., 2009; PEDROSO et al., 2009).

Alguns estudos relatam o efeito negativo dos extratos de plantas de gengibre (Zingiber officinale), cravo-da-índia (Caryophyllus aromaticus L.) e de alho (Allium sativum L.) sobre os microrganismos fitopatógenos, mas, pouco se sabe de seu potencial na proteção de plantas de tomateiro à pinta preta (BRITO; NASCIMENTO, 2015; VENTUROSO et al., 2011). Assim, objetivou-se avaliar o potencial efeito protetor dos extratos de plantas de gengibre ( $Z$. officinale), cravo-daíndia (C. aromaticus L.) e de alho (A. sativum L.) no controle da pinta preta do tomateiro.

\section{MATERIAL E MÉTODOS}

O experimento in vitro foi conduzido no laboratório de Fitopatologia da Universidade Federal da Fronteira Sul no Campus Laranjeiras do Sul Paraná. As coordenadas geográficas da região são $25^{\circ} 26^{\prime} 42$ "' de latitude Sul e 52'26'29' longitude Oeste. O experimento in vivo foi realizado em casa de vegetação do Sítio Iraí no interior do município de Nova Laranjeiras (PR). O trabalho foi conduzido sob cultivo protegido com temperatura de aproximadamente $25^{\circ} \mathrm{C} \pm 2{ }^{\circ} \mathrm{C}$ e umidade relativa média de $79,5 \%$.

\section{Obtenção de Extratos Aquosos Vegetais}

Os materiais vegetais rizoma do gengibre (Zingiber officinale), botões florais do cravo-da-índia (Caryophyllus aromaticus L.) e bulbos do alho (Allium sativum L.) foram adquiridos no comércio local do município de Laranjeiras do Sul -PR. Os materiais foram lavados com água destilada e em seguida triturados em liquidificador separadamente por três minutos. Para cada material vegetal utilizou-se $200 \mathrm{~g}$ em 1000 $\mathrm{mL}$ de água destilada, para obtenção do extrato bruto aquoso na concentração de $20 \%$. Em seguida, o material foi filtrado em gaze. A partir desse extrato foram preparadas as concentrações de $1,0,5,0,10$ e 15 e $20 \%$ e em seguida utilizadas nos bioensaios.

\section{Obtenção e Manutenção do fungo}

Para a implantação dos experimentos foi coletado inóculo da A. solani em plantas de tomateiro sintomáticas cultivadas pelo produtor do município de Laranjeiras do Sul PR. O isolado obtido foi mantido em meio de cultura ÁgarBatata-Dextrose- (BDA), repicado a cada sete dias e mantidos em estufa BOD (body oxigen demand) a $25^{\circ} \mathrm{C} \pm 2{ }^{\circ} \mathrm{C}$ no escuro. 
A obtenção de esporos de A. solani para os testes in vivo e in vitro, foi realizada através de ferimento com agulha histológica no ápice do fruto de tomate adicionando-se a massa micelial do patógeno. Em seguida, o fruto foi mantido em câmara úmida por 10 dias a $25{ }^{\circ} \mathrm{C} \pm 2{ }^{\circ} \mathrm{C}$. Esse procedimento foi adotado pois, não foi obtida esporulação suficiente em placa de Petri, nas condições desse trabalho.

O preparo da suspensão de esporos do fungo foi realizado através da lavagem dos frutos em água destilada, fazendo-se a remoção dos esporos pela raspagem com pincel. A suspensão foi filtrada em gaze e o número de esporos por $\mathrm{mL}$ foi determinando através da câmera de Neubauer ao microscópio óptico.

\section{Ensaio antifúngico in vitro}

No teste in vitro, os extratos aquosos brutos de gengibre, cravo-da-índia e alho nas concentrações de 1,0, 5,0, 10, 15 e $20 \%$ foram adicionados ao meio BDA e autoclavados a 121 ${ }^{\circ} \mathrm{C}$ por $20 \mathrm{~min}$. Também como tratamento utilizou-se meio $\mathrm{BDA}+0,25 \%$ de calda bordalesa. Como testemunha utilizouse meio BDA e água destilada. Após a autoclavagem, os meios de cultura foram vertidos em placas de Petri. Duas horas após, discos de $5 \mathrm{~mm}$ de diâmetro, contendo micélio de A. solani com sete dias de idade foram repicados para o centro de cada placa, essas foram mantidas a $30^{\circ} \mathrm{C}$ por 7 dias em escuro. As avaliações do crescimento micelial foram realizadas após 48 hs do início do teste, medindo-se o diâmetro médio $(\mathrm{cm})$ da colônia por 5 dias.

Para o teste de inibição de germinação, os tratamentos utilizados foram: testemunha água destilada estéril, calda bordalesa a $0,25 \%$ e os extratos bruto aquosos de gengibre, cravo-da-índia e alho nas concentrações de 1,0, 5,0, 10, 15 e $20 \%$, submetidos ou não a autoclavagem. Em cada célula da placa de Elisa foi adicionado $30 \mu \mathrm{L}$ de suspensão a $1 \times 10^{4}$ de esporos por $\mathrm{mL}$ e $30 \mu \mathrm{L}$ de cada um dos tratamentos descrito anteriormente. Após 20 h, realizou-se a contagem de 100 esporos germinados por parcela e emissão de tubos germinativos em câmara de Neubauer ao microscópio óptico. Também foi avaliado o tamanho dos tubos germinativos em microscópio óptico, pela medição de 10 tubos germinativos por parcela.

O delineamento experimental utilizado foi inteiramente casualizado, com cinco repetições. Os dados obtidos foram submetidos a análise de variância e análise de regressão utilizando-se o programa SISVAR 5.6 (FERREIRA, 2011).

\section{Ensaio in vivo proteção em plantas}

Sementes de tomateiro, cv. Santa Cruz Kada, foram semeadas em bandejas de isopor de 200 células contendo substrato comercial Aos 30 dias após a semeadura, as plantas foram transplantadas para vasos de 5 litros contendo solo. As plantas foram mantidas em casa de vegetação, sendo uma muda de tomate por vaso. $\mathrm{O}$ espaçamento entre as plantas de tomateiro foi de $1 \mathrm{~m}$ entre linha e $0,5 \mathrm{~m}$ entre planta em sistema tutorado. Cada parcela foi composta por duas plantas.

As plantas de tomateiro foram submetidas aos seguintes tratamentos: testemunha água (T1); extrato aquoso bruto de extrato de gengibre $20 \%$ (T2), extrato aquoso bruto de bulbo de alho $20 \%$ (T3), extrato aquoso bruto cravo-da-índia $20 \%$ (T4) e calda bordalesa (2,5 g/L de água) (T5).

As aplicações com os tratamentos foram realizadas na superfície foliar do tomateiro até o ponto de escorrimento, sendo iniciadas após 47 dias do transplante (DAT) das mudas até o momento da colheita dos frutos de tomateiro, uma vez por semana. O equipamento utilizado para aplicação dos tratamentos foi um pulverizador costal de 12 litros com bico cônico.

A inoculação do fitopatógeno, A. solani no tomateiro foi realizada aos 49 DAT utilizando um borrifador até o molhamento completo da superfície da folha com a suspensão na concentração de $1 \times 10^{4}$ conídios $\mathrm{mL}^{-1}$. As plantas foram mantidas em câmara úmida por um período de $20 \mathrm{~h}$ após a inoculação do patógeno.

A avaliação da severidade do patógeno na planta de tomateiro teve início quando apareceram os primeiros sintomas da doença nas plantas do tratamento testemunha e repetidas semanalmente. As avaliações foram realizadas nas folhas marcadas (4 folhas marcadas em cada planta com uma fita) pertencentes ao terço médio das plantas de cada parcela. A avaliação da severidade foi realizada com o auxílio da escala diagramática de Boff (1988), com cinco níveis de severidade de área foliar lesionada.

A partir dos dados obtidos na avaliação da severidade do patógeno foi calculada a Área Abaixo da Curva de Progresso da Doença (AACPD). O cálculo da AACPD foi realizado de acordo com a equação 1 .

\section{$\mathrm{AACPD}=\sum(\mathrm{Xi}+\mathrm{Xi}+1) / 2(\mathrm{t} \mathrm{i}+1-\mathrm{t} \mathrm{i})$}

(Eq. 1)

Em que: $X=$ severidade média da doença por planta; $X=x$ (t1); n= número de avaliações; ( $\mathrm{t}$ i+1- ti) é o intervalo entre duas avaliações consecutivas (SHANER; FINNEY, 1977).

Avaliou-se a produtividade do tomateiro, determinandose a pesagem e o número de frutos por planta. $\mathrm{O}$ delineamento utilizado foi o delineamento inteiramente casualizado (DIC), com cinco tratamentos e com cinco repetições, assim totalizando 25 parcelas e cada parcela constituída por 2 plantas. Os dados obtidos da AACPD e os dados referentes aos números de frutos e os valores da produtividade do tomateiro foram submetidos e comparados através do teste de Tukey a $5 \%$ de probabilidade de erro, pelo programa SISVAR 5.6 (FERREIRA, 2011).

\section{RESULTADOS E DISCUSSÃO}

\section{Efeito dos extratos vegetais no crescimento micelial de Alternaria solani}

Os resultados obtidos do efeito dos extratos sobre o crescimento micelial de A. solani são apresentados na Figura 1. Os extratos das três espécies vegetais inibiram o crescimento micelial. Para os extratos de gengibre e alho obteve-se significativa equação linear, com redução no crescimento micelial conforme o aumento na concentração do extrato. Na concentração de $20 \%$ a inibição foi de 37,9 e $70,0 \%$ para os extratos de gengibre e alho em relação a testemunha contendo apenas meio de cultivo com água, respectivamente.

Resultados semelhantes foram encontrados por Harish et al. (2004) e Amaral; Bara (2005) em que observaram in vitro, utilizando o extrato de gengibre, inibição de $70 \%$ do crescimento do fungo Helminthosporium oryzae Breda de Hann, agente causal da mancha parda do arroz.

Esta significativa atividade antifúngica do extrato de gengibre possivelmente está relacionada à interferência do 
gengerol, que tem ação antioxidante ou inibidor de biossíntese do fungo (SURH, 2002).

Brito e Nascimento (2015) utilizando-se extrato de gengibre demonstrou a eficiência do mesmo em outro patossistema. Esses autores observaram que, aumentando-se a concentração do extrato de gengibre, maior é o potencial de inibição do desenvolvimento micelial de Curvularia eragrostidis (P. Henn). Meyer, fungo responsável pela queima das folhas do inhame.

Em estudos realizados por Ferreira et al. (2013), mostraram que, em diferentes concentrações, o óleo essencial de gengibre reduziu significativamente o crescimento, germinação e esporulação da espécie Aspergillus flavus.

Pedroso et al. (2009) já haviam avaliado o efeito do extrato de gengibre in vitro e indicaram que o aumento da concentração do gengibre é eficiente na redução micelial da A. solani.

A calda bordalesa proporcionou $100 \%$ de inibição do crescimento micelial, confirmando seu efeito antifúngico. $\mathrm{O}$ extrato de cravo-da-índia também promoveu inibição de $100 \%$ no crescimento micelial em todas as concentrações, indicando elevado efeito antifúngico sobre A. solani mesmo em baixas concentrações, portanto maior efeito sobre esse fitopatógeno em relação aos extratos das outras espécies vegetais. Observando a equação de regressão, para cada $1 \%$ de aumento na concentração de extrato de alho houve inibição em 0,2353 cm no crescimento do fungo (Figura 1).

Figura 1. Crescimento micelial de Alternaria solani em função do tratamento com extratos brutos aquosos (EB) de gengibre, EB cravo-da-índia e EB de alho. CB: Calda bordalesa. EB: Extrato bruto aquoso.

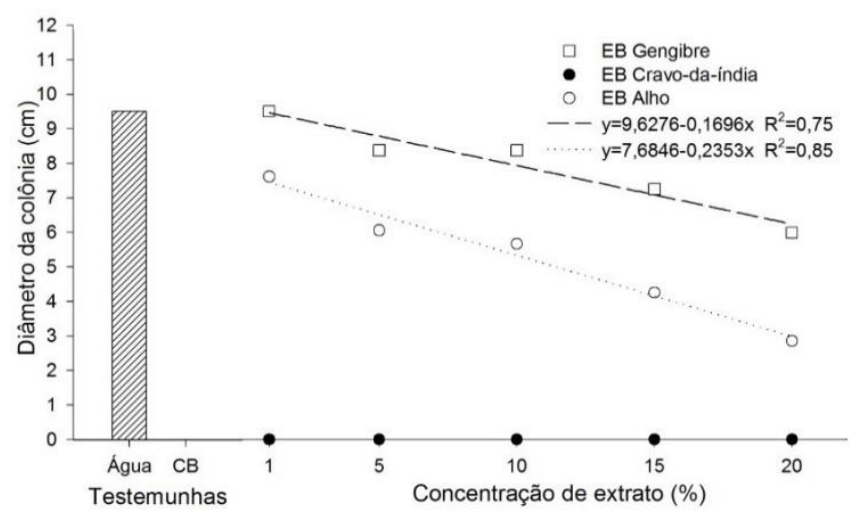

O extrato de alho promoveu maior redução no desenvolvimento micelial do patógeno quando comparado com o gengibre. Conforme menciona Souza et al. (2013) a ação antimicrobiana do extrato e óleo essencial do alho é devido à presença de seus componentes, dentre esses a alicina, substância que atua sobre diversos microrganismos.

Dill (2009), demonstrou a ação antifúngica do extrato de alho no controle de $A$. solani in vitro. $\mathrm{O}$ autor, observou que a utilização do extrato filtrado a $30 \%$, reduziu o crescimento micelial de A. solani, 67,77\%. Ribeiro (1999) também observou atividade antifúngica do extrato de alho filtrado na redução do desenvolvimento micelial de Colletotrichum gloeosporioides. $\mathrm{O}$ autor ainda diz que, quando utilizou o extrato de alho autoclavado, este perdeu suas características antifúngicas durante o processo de esterilização.
Sallam (2011) avaliando o efeito de diferentes extratos de plantas, observaram que o extrato de alho (Allium sativum) na concentração de $5 \%$, inibiu o crescimento micelial de $A$. solani em $42,2 \%$ e, em plantas de tomateiro quando tratadas nesta mesma concentração reduziu a severidade da doença em $71,7 \%$.

O extrato de cravo-da-índia promoveu resultados semelhantes à calda bordalesa, com inibição total do crescimento micelial, mesmo em menores concentrações. Resultados obtidos por Oliveira et al. (2016) para outro patossistema evidenciaram que o extrato de cravo-da-índia foi efetivo na inibição do crescimento micelial de Colletotrichum musae, equivalendo ao tratamento com fungicida, inibindo o crescimento micelial do patógeno em $100 \%$, em todas as concentrações testadas $(5,10,15,20,25$ e $30 \%)$.

A espécie Caryophyllus aromaticus (cravo-da-índia), obtida como extrato bruto quanto na forma de óleo essencial, vem se destacando no controle de doenças, apresentando grande eficiência como agente antimicrobiano, sugerindo-se que essa ação pode ser devido a atuação de componentes químicos, como o eugenol ou ao cariofileno ou a essas duas substâncias que são os principais constituintes dessa planta medicinal (AMARAL, 2005).

Resultados semelhantes ao presente trabalho foi obtido por Santos Neto et al., (2016), quanto a inibição do crescimento micelial de Alternaria solani e Septoria lycopersici, utilizando extrato aquoso, óleo essencial e citral provenientes do capim-limão (Cymbopogon citratus), sendo que o óleo essencial e o citral na maior concentração testada de $400 \mu \mathrm{L} / \mathrm{L}^{-1}$ proporcionaram $100 \%$ de inibição, demonstrando potencial alternativa para manejo fitossanitário da cultura do tomate.

Sadana e Didwania (2015) estudaram a bioeficácia de quinze espécies vegetais (Polyalthia longifolia, Azadirachta indica, Datura stramonium, Ocimum sanctum, Calotropis procera, Crotalaria juncea, Eucalyptus obliqua, Cassia fistula, Agele marmelos, Croton bonplonadium, Pergularia daemia, Cleome viscose, Phyllanthus amarus, Bauhinia purpurea, Euphorbia hirta), in vitro sob Alternaria solani. Os autores observaram que o extrato aquoso bruto de Eucalyptus obliqua $15 \%$, foi o mais eficiente, inibindo $88 \%$ o crescimento micelial do fungo. As espécies Datura stamonium, Azadirachta indica, Calotropis procera e Polyalthia longifolia inibiram o crescimento micelial em $82,5 \%, 73,7 \%, 79 \%$ e $76,7 \%$, respectivamente.

Resultados diferentes ao obtido pelo presente trabalho, foram observados por Itako et al. (2008) que verificaram que o crescimento micelial do fungo $A$. solani foi igual ou superior à testemunha nos extratos brutos aquosos das plantas testadas Achillea millefolium (mil-folhas), Artemisia camphorata (cânfora), Cymbopogon citratus (capim-limão) e Rosmarinus officinalis (alecrim), indicando que estes extratos não impediram o crescimento do fungo $A$. solani in vitro.

Nos estudos de Domingues et al. (2011) foi avaliado a eficácia dos extratos de plantas Senna spectabilis, Senna multijuga e Avicennia schaueriana e duas espécies de basidiomicetos, Oudemansiella canarii (CCB179) e Irpex lacteus (CCB196) na inibição do in vitro do crescimento micelial e germinação de três patógenos, dentre eles $A$. solani. Estes autores observaram que apenas o extrato fúngico $O$. canarii inibiu totalmente a germinação de conídios de $A$. solani. Já os demais extratos não apresentam nenhum grau de inibição da germinação de conídios. Para o crescimento 
micelial os extratos de plantas não tiveram diferença significativa em relação a testemunha.

Goussous e colaboradores (2010) avaliaram em sua pesquisa a eficácia e a melhor dosagem de cinco extratos de plantas no controle de dois isolados de Alternaria solani (A6 e A13). Os autores observaram que todos os extratos de plantas, manjerona da síria (Majorana syriaca), alecrim (Rosmarinus officinalis), sálvia grega (Salvia fruticosa), vinagreira (Hibiscus sabdariffa) e lavanda algodão (Santolina chamaecyparissus), foram eficazes na redução do crescimento micelial de A. solani em relação ao controle.

Dentre estes, destaca-se os extratos das espécies vegetais vinagreira a $8 \%$ e manjerona da síria a $10 \%$ que inibiram totalmente o crescimento micelial de A. solani. O extrato de alecrim também inibiu $100 \%$ do crescimento micelial, porém, sua concentração foi o dobro para os extratos de vinagreira e manjerona da síria. Deste modo, para o extrato de alecrim a $10 \%$ não foram observadas diferenças significativas em relação ao tratamento controle (GOUSSOUS et al. 2010).

Tomazoni et al. (2013) em testes realizados in vitro com o óleo essencial de Cinnamomum zeylanicum sob os fungos, Alternaria solani, Stemphylium solani e Septoria lycopersici, verificaram a inibição do crescimento de A. solani e $S$. solani a partir da concentração $0,5 \mu \mathrm{L} / \mathrm{mL}$ e para $S$. lycopersici a partir da concentração $0,1 \mu \mathrm{L} / \mathrm{mL}$.

\section{Efeito dos extratos vegetais na germinação dos esporos da Alternaria solani}

Os resultados do efeito dos extratos autoclavado e não autoclavado sobre a germinação da $A$. solani são apresentados na Figura 02 e 03, respectivamente.

Os extratos das três espécies vegetais promoveram inibição na germinação dos esporos. Para os extratos autoclavados e não autoclavado de gengibre, alho e o cravoda-índia obteve-se significativa equação linear, com redução na germinação conforme o aumento na concentração do extrato. Na concentração de $20 \%$ apenas de 47,5 e $16 \%$ dos esporos germinaram para os extratos de gengibre e alho não autoclavados, respectivamente. Na concentração de $20 \%$ apenas 59 e $27,5 \%$ dos esporos germinaram para os extratos de gengibre e alho autoclavados, respectivamente.

Figura 2. Germinação de esporos de Alternaria solani em função ao tratamento com extratos brutos aquosos (EB) autoclavados de gengibre, cravo-da-índia e alho. CB: Calda bordalesa. EB: Extrato bruto aquoso.

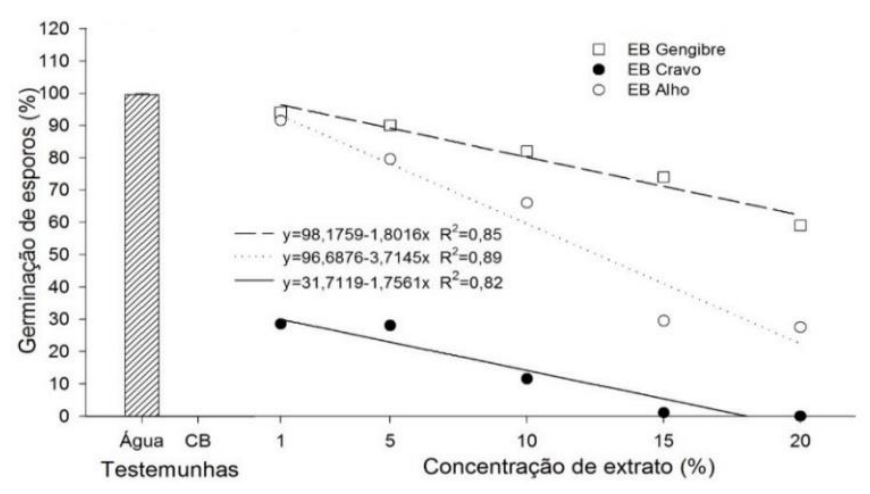

Para o extrato de cravo-da-índia tanto autoclavado e não autoclavado na concentração de $20 \%$ inibiram em $100 \%$ a germinação dos esporos, indicando elevado efeito antifúngico sobre A. solani. Assim os extratos tanto autoclavado e não autoclavado possuem a capacidade em reduzir a germinação dos esporos da doença, indicando característica termoestável desses extratos.

Para o extrato cravo-da-índia não autoclavado observase que, mesmo na menor concentração houve inibição da germinação de esporos de A. solani, chegando a $100 \%$ de inibição com o aumento da concentração do extrato bruto (Figura 3).

Figura 3. Germinação de esporos de Alternaria solani em função ao tratamento com extratos brutos aquosos (EB) não autoclavados de gengibre, cravo-da-índia e alho. CB: Calda bordalesa. EB: Extrato bruto aquoso.

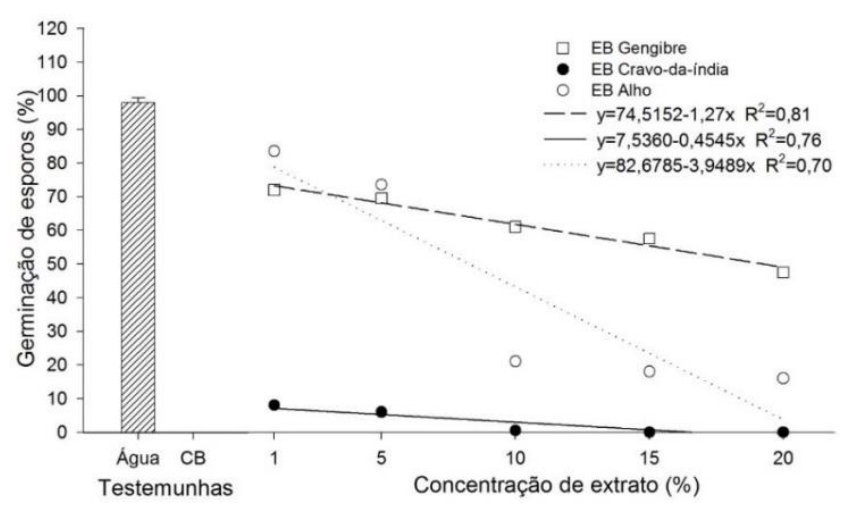

Resultados semelhantes a esta pesquisa foram obtidos por Goussous e colaboradores (2010) que observaram efeito fungitóxico dos extratos de vinagreira e manjerona da síria sob A. solani. Os autores relatam que mesmo na menor concentração dos extratos (1\%) houve inibição da germinação de conídios do patógeno de 91,9 e $82,5 \%$, para os respectivos extratos. Os autores ainda ressaltam que, os resultados de tais investigações indicaram que a inibição no crescimento micelial e na germinação de esporos varia muito, em função das diferentes espécies de plantas utilizadas, método de preparação e concentração.

Segundo Itako et al. (2008) os extratos vegetais podem apresentar propriedade antagônica ao desenvolvimento de fungos. Esses autores observaram que os extratos brutos aquosos de Achillea millefolium (mil-folhas), Artemisia camphorata (cânfora), Cymbopogon citratus (capim-limão) e Rosmarinus officinalis (alecrim) autoclavados, não impediram o crescimento micelial do fungo A. solani quando comparado a testemunha (água). No entanto, os autores observaram que para a produção de conídios, os extratos de cânfora e capimlimão nas concentrações de 20 e $40 \%$, reduziram significativamente a esporulação em 91,5; 98,4; 93,2 e 99,0\%, respectivamente.

Em estudos realizados por Rodrigues et al. (2007) indicam atividade antimicrobiana de extratos bruto aquoso de gengibre, inibindo o crescimento micelial e a produção de escleródios de Sclerotinia sclerotiorum em alface. O óleo essencial de gengibre não do tratamento com fungicida Tecto, quanto à inibição da germinação de esporos do fungo Penicillium digitatum (MATTOS, 2010).

Em estudos realizados por Almeida, Camargo e Panizzi (2009) para o controle de Colletotrichum acutatum em morangueiro, foram testados os extratos de plantas medicinais, das quais arruda, gengibre, vinca, losna, cebola, 
arnica e nim foram os que propiciaram melhor inibição da germinação dos conídios, diferindo estatisticamente da testemunha.

Quanto ao tamanho médio dos tubos germinativos de $A$. solani em função dos tratamentos, obteve-se resultados semelhantes ao da germinação de esporos. Os derivados das três espécies vegetais promoveram redução no tamanho dos tubos germinativos conforme aumento na concentração do extrato, mostrando significativo efeito fungistático dos extratos sobre o fitopatógeno. Esse resultado foi observado tanto quando autoclavados (Figura 04) e quando não autoclavados (Figura 05), indicando a presença de compostos ativos termoestáveis. Esse resultado está pertinente com os observados para germinação e crescimento micelial, mostrando efeito não apenas na germinação como também no crescimento das hifas.

Figura 4. Tamanho de tubos germinativos de Alternaria solani em função ao tratamento com extratos brutos aquosos (EB) autoclavados de gengibre, cravo-da-índia e alho. CB: Calda bordalesa. EB: Extrato bruto aquoso.

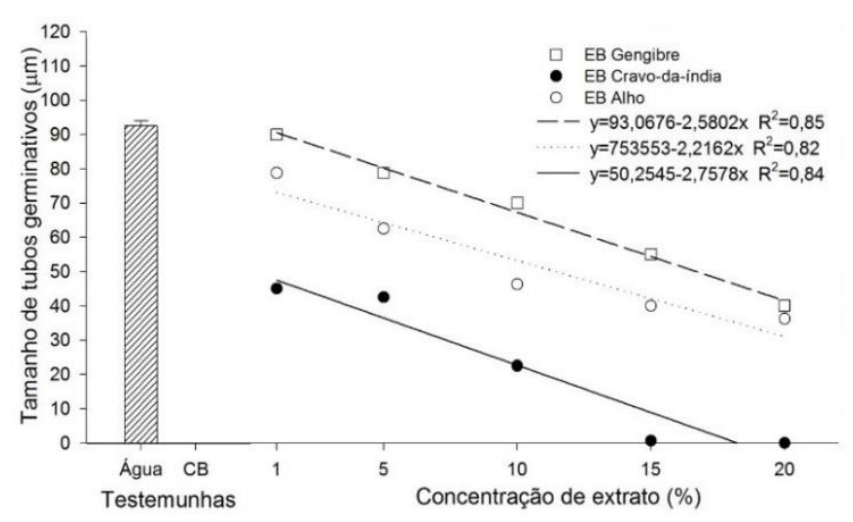

Figura 5. Tamanho de tubos germinativos de Alternaria solani em função ao tratamento com extratos brutos aquosos (EB) não autoclavados de gengibre, cravo-da-índia e alho. CB: Calda bordalesa. EB: Extrato bruto aquoso.

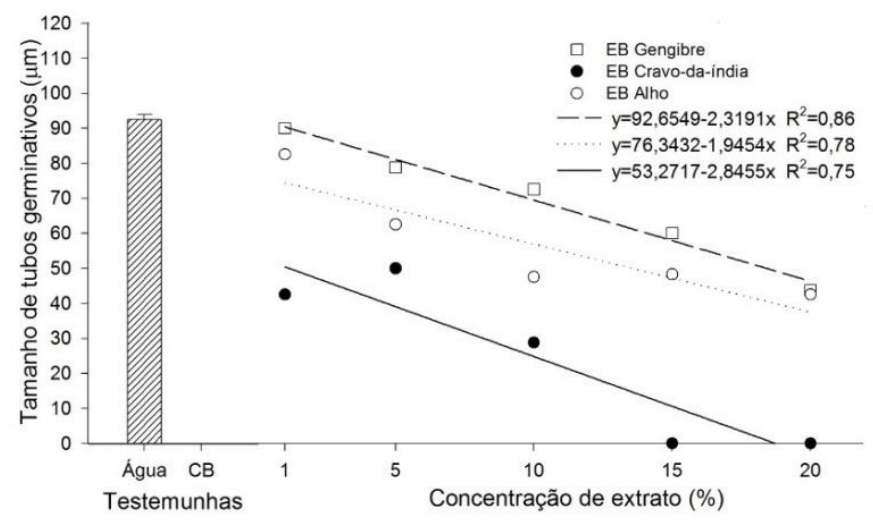

No trabalho desenvolvido por Fiori et al. (2000) foi observado o efeito fungitóxico do óleo essencial de $A$. millefolium (mil-folhas) em Didymella bryoniae sendo que, na alíquota de $100 \mu \mathrm{L}$, foi identificada inibição de $96 \%$ da germinação de conídios, além disso observaram também através de microscopia eletrônica de varredura, crescimento atípico e degeneração das hifas de $D$. bryoniae.
Avaliação “in vivo” da produção do tomateiro e da severidade da pinta preta

Com relação a produção das plantas de tomateiro tratadas com os extratos vegetais, observou-se que não houve diferença significativa entre os tratamentos com os extratos sobre o número e peso de frutos de tomate aos 90 dias após emergência (Tabela 1).

Quanto a severidade da doença, todos os tratamentos promoveram redução na área abaixo da curva de progresso da doença (AACPD) em relação a testemunha água destilada (Tabela 1). Maior redução na severidade foi promovida pela calda bordalesa, que reduziu em 94,3\% a AACPD em relação a testemunha água.

Entre os extratos vegetais, o cravo-da-índia foi que apresentou maior eficiência na redução da severidade da doença no tomateiro. A área foliar infectada pela doença na última avaliação foi de $16 \%$, enquanto que o gengibre e o alho foi de 26 e $25 \%$, respectivamente. Desta forma, através dos valores da AACPD o gengibre e o alho não se diferiram entre si, mostrando efeito semelhante no controle da doença. A redução na AACPD foi de 55,8, 29,5 e 22,5\% para extratos de cravo-da-índia, alho e gengibre em relação a testemunha água, respectivamente.

Tabela 1. Média de números de frutos, pesos dos frutos e área abaixo da curva de progresso da doença (AACPD) pinta preta em plantas de tomateiro tratadas com diferentes extratos vegetais.

\begin{tabular}{lccc}
\hline Tratamentos & $\begin{array}{c}\text { Números de } \\
\text { frutos * }\end{array}$ & $\begin{array}{c}\text { Peso dos } \\
\text { frutos }(\mathrm{g}) *\end{array}$ & AACPD \\
\hline Água destilada & 25,6 & 463,6 & $188,4 \mathrm{a} * *$ \\
Gengibre & 27,0 & 458,2 & $146,0 \mathrm{~b}$ \\
Alho & 22,4 & 436,4 & $132,8 \mathrm{~b}$ \\
Cravo-da-índia & 23,2 & 405,8 & $83,2 \mathrm{c}$ \\
Calda bordalesa & 32,6 & 612,8 & $10,8 \mathrm{~d}$ \\
\hline CV\% & 25,6 & 38,0 & 9,34 \\
\hline
\end{tabular}

*Diferenças entre médias não significativas pela análise de variância e teste de Tukey ao nível de $5 \%$ de probabilidade para número de frutos e peso dos frutos. **As médias seguidas pela mesma letra não se diferem estatisticamente entre si pelo teste de Tukey ao nível de $5 \%$ de probabilidade para AACPD.

No trabalho de Dill (2009) foi verificado que extratos vegetais tiveram influência sobre a pinta preta do tomateiro e desta forma influenciando no desenvolvimento e ganho de peso dos frutos de tomateiro. Balbi-Peña et al. (2006) também obtiveram aumento na produtividade com extratos brutos. Em seu trabalho com extratos vegetais de Curcuma longa obteve resultados de controle da doença e produtividade em tomateiro foi similar aos obtidos com fungicidas cúpricos.

Abreu (2006) observou em sua pesquisa diminuição da incidência da pinta preta em folíolos de tomate doente através do controle alternativo com a utilização dos óleos essenciais de Cymbopogon citratus e Caryophyllus aromaticus na avaliação de folíolos doentes.

Os resultados desta pesquisa mostram o potencial dos extratos vegetais avaliados para controle alternativo da pinta preta do tomateiro, podendo representar opção na produção de tomate em sistema de base ecológica.

\section{CONCLUSÕES}

Os extratos vegetais avaliados apresentaram atividade direta sobre A. solani, inibindo o crescimento micelial, a 
germinação e o alongamento dos tubos germinativos, com destaque para o extrato de cravo-da-índia.

A atividade antifúngica dos extratos sobre A. solani não foi afetada de forma mais expressiva pela autoclavagem, indicando possivelmente a presença de compostos ativos termoestáveis.

Os extratos de cravo-da-índia, alho e gengibre reduziram significativamente a severidade da pinta preta em plantas de tomateiro, embora não tenham afetado variáveis de produção nas condições do experimento.

\section{AGRADECIMENTOS}

Os autores agradecem
MCTI/MAPA/MDA/MEC/MPA/CNPq a
apoio financeiro.

\section{REFERÊNCIAS}

ABREU C. L. M. Controle de Alternaria solani em tomateiro (Lycopersicon esculentum) com óleos essenciais. 2006. 82 f. Tese (Doutorado em Agronomia - Horticultura) Universidade Estadual Paulista, Faculdade de Ciências Agronômicas, Botucatu, 2006.

ALMEIDA, T. F.; CAMARGO, M.; PANIZZI, R. C. Efeito de extratos de plantas medicinais no controle de Colletotrichum acutatum, agente causal da flor preta do morangueiro. Summa Phytopathologica, v.35, n.3, p.196-201, 2009.

AMARAL, M. F. Z. J; BARA, M.T.F. Avaliação da atividade antifúngica de extratos de plantas sobre o crescimento de fitopatógenos. Revista Eletrônica de Farmácia, Suplemento, v. 2 n. 2, p. 5-8, 2005.

ANVISA, AGÊNCIA NACIONAL DE VIGILÂNCIA SANITÁRIA. Programa de análise de resíduos de agrotóxicos em alimentos - PARA: relatório 2013 e 2015. Brasília, DF, 2016. 246p.

ARAÚJO A. C.; NOGUEIRA, D. P.; AUGUSTO, L. G. Impacto dos praguicidas na saúde: estudo da cultura de tomate. Revista Saúde Pública, v.34, n.3, p.309-313, 2000.

ARAUJO, J. C. A.; MATSUOKA, K. Histopatologia da interação Alternaria solani e tomateiros resistente e suscetível. Fitopatologia Brasileira, v.29, p.268-275, 2004.

BALBI-PEÑA, M. I.; BECKER, A.; STANGARLIN, J. R.; FRANZENER, G.; LOPES, M. C.; SCHWAN-ESTRADA, K. R. F. Controle de Alternaria solani em tomateiro por extratos de Curcuma longa e Curcumina - II. Avaliação in vivo. Fitopatologia Brasileira, Marechal Cândido Rondon-PR , v. 31, n. 4, p. 401-404, 2006.

BOFF, P. Epidemiologia e controle químico da mancha de estenfílio (Stemphylium solani Weber) e da pinta preta (Alternaria solani (Ellis e Martin) Jones e Grout) em dois sistemas de condução do tomateiro (Lycopersicon esculentum Mill.). 1988. 192 p. Dissertação (Mestrado em Agronomia/Fitopatologia). Universidade Federal de Viçosa, Viçosa MG,1988.
BRITO, N. M.; NASCIMENTO, L. C. Fungitoxic potential of plant extracts on in vitro Curvularia eragrostidis (P. Henn.) Meyer. Revista Brasileira de Plantas Medicinais. v.17 n.2, p.230-238, 2015.

DILL, A. M. Extratos vegetais no controle da pinta preta (Alternaria solani) em tomateiro. 2009. 55 p. Dissertação (Mestrado em Agronomia). Universidade Federal de Santa Maria, Santa Maria-RS, 2009.

DOMINGUES, R. J.; YOUNG, M. C. M.; TÖFOLI, J. G.; MATHEUS, D. R. Avaliação do potencial antifúngico de extratos de plantas e de basidiomicetos nativos sobre Colletotrichum acutatum, Alternaria solani e Sclerotium rolfsii. Summa Phytopathologica, v.37, n.3, p.149-151, 2011.

FAWZI, E. M, KHALIL, A. A, AFIFI, A. F. Antifungal effect of some plant extracts on Alternaria alternata and Fusarium oxysporum. African Journal Biotechnology, v.8, n.1, p. 2590-2597, 2009.

FAO-FAOSTAT. Database Results-2010. Disponível em:< http://faostat.fao.org/site/567/DesktopDefault.aspx?PageID=5 67\#ancor>. Acesso em 23 marc. 2017.

FERREIRA, D. F. Sisvar: A computer statistical analysis system. Ciência e Agrotecnologia, Lavras, v.35, n.6, p.10391042, 2011.

FERREIRA, F.D.; MOSSINI, S. A. G.; FERREIRA, F. M. D.; ARROTÉIA, C. C.; COSTA, C. V. N.; JUNIOR, M. M. The Inhibitory Effects of Curcuma longa L. Essential Oil and Curcumin on Aspergillus flavus Link Growth and Morphology. The Scientific World Journal, 2013, p.6.

FILGUEIRA, F. A. R. Novo Manual de Olericultura: agrotecnologia moderna na produção e comercialização de hortaliças. 3. ed: Viçosa: UFV, 2007, p. 412.

FIORI, A. C. G.; SCHWAN-ESTRADA, K. R. F.; STANGARLIN, J. R.; VIDA, J. B.; SCAPIM, C. A.; CRUZ, M. E. S.; PASCHOLATI, S. F. Antifungal activity of leaf extrats and essential oils of some medicinal plants against Didymella bryoniae. Journal of Phytopathology, v.148, n. 7-8, p.483-487, 2000.

FRANZENER, G.; BALBI-PEÑA, M. I.; ASSI, L.; STANGARLIN, J. R.; PORTZ, R. L. Controle da pinta preta do tomateiro pelo extrato de cúrcuma: um estudo de caso sobre a sustentabilidade. Scientia Agraria Paranaensis, v.8, n.1-2, p.99-112, 2009.

GOUSSOUS, S. J.; EL-SAMENA, F. M.;TAHHAN, R. A. Antifungal activity of several medicinal plants extracts against the early blight pathogen (Alternaria solani). Archives of Phytopathology and Plant Protection, v. 43, n. 17, p.1745$1757,2010$.

HARISH, S.; SARAVANAN, T.; RADIACOMMARE, R.; EBENEZAR, E. G.; SEETHARAMAN, K. Mycotoxic effect of seed extracts against Helminthosporium oryzae Breda de 
Hann, the incitant of rice brown spot. Journal of Biological Sciences, v.4, p.366-369, 2004.

HUANG, Y.; ZHAO, J.; ZHOU, L.; WANG, J.; GONG, Y.; CHEN, X.; GUO, Z.; WANG, Q.; JIANG, W. Antifungal Activity of the Essential Oil of Illiciu'm verum Fruit and Its Main Component trans-Anethole. Molecules. v.15, n.11, p.7558- 7569, 2010.

IBGE. Instituto Brasileiro de Geografia e Estatística. Levantamento sistemático da produção agrícola, Rio de Janeiro, v. 29, n. 8, p. 1-79, ago. 2015.

ITAKO, A. T.; SCHWAN-ESTRADA, K. R. F.; TOLENTINO, J. B.; STANGARLIN, J. R.; CRUZ, M. E. S. Atividade antifúngica e proteção do tomateiro por extratos de plantas medicinais. Tropical Plant Pathology, v. 33, n.3, p.241-244, 2008.

JANTASORN, A., MOUNGSRIMUANGDEE, B. AND DETHOUP, $T$. In vitro antifungal activity evaluation of five plant extracts against five plant pathogenic fungi causing rice and economic crop diseases. Journal of Biopesticides, v.9, n.1, p.1-7, 2016.

KISHORE, G. K, PANDE, S. Evaluation of essential oils and theircomponents for broad-spectrum antifungal activity and control of late leaf spot and crown rot diseases in peanut. Plant Disease. 91:375- 379, 2007.

KUROZAWA, C.; PAVAN, M. A. Doenças do tomateiro (Lycopersicon esculentum). In: KIMATI, H.; AMORIM, L.; REZENDE, J. A. M.; BERGAMIN FILHO, A.; CAMARGO, L. E. A. (Org.). Manual de fitopatologia: Doenças das plantas cultivadas. 4. ed. São Paulo: Agronômica Ceres, 2005a. p. 607-626.

MATTOS, L. P. V. de. Controle de Guignardia citricarpa e Penicillium digitatum em laranja com óleos essenciais e agentes de biocontrole. Tese (Doutorado) - Universidade Estadual Paulista, Botucatu, 2010. $94 \mathrm{f}$.

MIRANDA, B. E. C.; RELS, A. Caracterização de isolados de Phytophthora infestans obtidos de tomateiro. Brasilia-DF: [s.n.], 2006. $17 \quad$ P. $\quad$ Disponível em: <http://www.infoteca.cnptia.embrapa.br/bitstream/doc/78028 8/1/bpd15.pdf> Acesso em: 25 de maio de 2014.

OLIVEIRA, E. S. de.; VIANA, F. M. P.; MARTINS, M. V. V. Alternativas a fungicidas sintéticos no controle da antracnose da banana. Summa Phytopathologica, v.42 n.4, p.340-350, 2016.

PEDROSO, D.; MENEZES, V.; JUNGUES, E.; MULLER, J.; GIRARDI, L.; DILL, A.; MUNIZ, M.; BLUME, E. Potencial Inibitório in vitro de Alternaria solani Sob Efeito de Extratos Botânicos. Revista Brasileira de Agroecologia, Santa Maria, v. 4, n, p. 4260-4263, nov. 2009.

RIBEIRO, L. F.; BEDENDO, I. P. Efeito inibitório de extratos vegetais sobre Colletotrichum gloeosporioides agente causal da podridão de frutos de mamoneiro. Scientia Agricola, v.56, n.4, p.1267-1271, 1999.

RODRIGUES, E.; SCHWAN-ESTRADA, K. R. F.; FIORITUTIDA, A. C. G.; STANGARLIN, J. R.; CRUZ, M. E. S.
Fungitoxicidade, atividade elicitora de fitoalexinas e proteção de alface em sistema de cultivo orgânico contra Sclerotinia sclerotiorum pelo extrato de gengibre. Summa Phytopathologica, v.33, n.2, p.124-128, 2007.

SADANA, D; DIDWANIA, N. Bioefficacy of Fungicides and Plant Extracts against Alternaria solani Causing Early Blight of Tomato. International Conference on Plant, Marine and Environmental Sciences, v.1, n.2, p.38-42, 2015.

SANTOS NETO, J.; SCHWAN-ESTRADA, K. R. F.; TEMPORAL, W. M.; ANDRADE, L. M. de; SENA, J. O. A. de. Subprodutos de capim-limão no controle de septoriose do tomateiro em sistema de produção orgânica. Revista Brasileira de Agroecologia. v.11, n.1, p.35-44, 2016.

SALLAM, N. M. A. Control of tomato early blight disease by certain aqueous plant extracts. Plant Pathology Journal, vol. 10, p. 187-191, 2011.

SINGH, P.; SRIVASTAVA, D. Phytochemical Screening and In Vitro Antifungal Investigation of Parthenium Hysterophorus extracts against A. alternata. International Research Journal of Pharmacy, 4: p.190-193, 2013.

SHANER, G.; FINNEY, R. E. The effect of nitrogen fertilization on the expression of slow-mildewing resistance in knox wheat. Phytopathology, v. 70, p. 1183-1186, 1977.

SOUZA, L. S. S. Extratos aquosos de alho (Allium sativum L.) e sisal (Agave sisalana perrine) no controle de Aspergillus niger e da podridão vermelha do sisal. 2010. 79 p. Dissertação (Mestrado em Ciências Agrárias). Universidade Federal do Recôncavo da Bahia, Cruz Das Almas-Bahia, 2010.

SOUZA, L. S. S.; SOARES, A. C. F. Extrato aquoso de alho (Allium sativum L.) no controle de Aspergillus niger causador da podridão vermelha em sisal. Tecnológica, Santa Cruz do Sul, v. 17, n. 2, p. 124-128, 2013.

SURH, Y. Anti-tumor promoting potential of selected spice ingredients with antioxidative and anti-inflammatory activies: a short rewiew. Food and Chemical Toxicology, v.40, n.5, p.1091-7, 2002.

TAPWAL, A., NISHA; G. A.R. G, S., GUATAM, N.; KUMAR, R. In vitro antifungal potency of plant extracts against five phytopathogens. Brazilian Archives Biology and Technology, v.54, n.6, p.1093-1098, 2011.

TOMAZONI, E. Z.; GIANI, S. G.; RIBEIRO, R. T.S.; PAULETTI, G. F., SCHWAMBACH, J. Atividade antifúngica do óleo essencial de Cinnamomum zeylanicum Ness. sobre fungos fitopatogênicos do tomateiro (Lycopersicon esculentum Mill.). Cadernos de Agroecologia, v.8, n.2, p.1-5, 2013.

VENTUROSO, L. R.; BACCHI, L. M. A.; GAVASSONI, W. L.; CONUS, L. A.; PONTIM, B. C. A.; BERGAMIN, A. C. Atividade antifúngica de extratos vegetais sobre o desenvolvimento de fitopatógenos. Summa Phytopathologica. v.37 n.1, p.18-23, 2011. 